\title{
The Importance of 1,5-Oxygen...Chalcogen Interactions in Enantioselective Isochalcogenourea Catalysis
}

\author{
Claire M. Young, ${ }^{a}$ Alex Elmi, ${ }^{b}$ Dominic J. Pascoe, ${ }^{b}$ Rylie K. Morris, ${ }^{c}$ Calum McLaughlin, ${ }^{a}$ Andrew M. \\ Woods, ${ }^{a}$ Aileen B. Frost, ${ }^{a}$ Alix de la Houpliere, ${ }^{a}$ Kenneth B. Ling, ${ }^{d}$ Terry K. Smith, ${ }^{a}$ Alexandra M. Z. \\ Slawin, ${ }^{a}$ Patrick H. Willoughby, ${ }^{c *}$ Scott L. Cockroft ${ }^{\text {b* }}$ and Andrew D. Smith ${ }^{\text {a* }}$
}

\begin{abstract}
The importance of $1,5-\mathrm{O} \cdots \cdot$ chalcogen $(\mathrm{Ch})$ interactions in isochalcogenourea catalysis $(\mathrm{Ch}=\mathrm{O}, \mathrm{S}$, Se) is investigated. Conformational analyses of $\mathrm{N}$-acyl isochalcogenouronium species and comparison with kinetic data demonstrate the significance of 1,5$0 \cdots$ Ch interactions in enantioselective catalysis. Importantly, the selenium analogue demonstrates enhanced rate and selectivity profiles across a range of reaction processes including nitronate conjugate addition and formal [4+2] cycloadditions. A gram-scale synthesis of the most active selenium analogue was developed using a previously unreported seleno-Hugerschoff reaction, allowing the challenging kinetic resolutions of tertiary alcohols to be performed at 500 ppm catalyst loading. Density Functional Theory (DFT) and Natural Bond Orbital (NBO) calculations support the role of orbital delocalization (occurring via intramolecular chalcogen bonding) in determining the conformation, equilibrium population, and reactivity of $\mathrm{N}$-acylated intermediates.
\end{abstract}

Non-covalent interactions play vital roles in governing chemical reactions, the conformation of small molecules, and the threedimensional structure of biomacromolecules. ${ }^{[1]}$ Hydrogen bonding has been widely exploited in organocatalysis for controlling conformation, reactivity and stereoselectivity. ${ }^{[2]}$ More recently, unconventional interactions, such as halogen bonding, ${ }^{[3]}$ cation- $\pi$ ${ }^{[4]}$ and anion- ${ }^{[5]}$ interactions have also been utilized. Nonbonding interactions are commonly used as the primary force for forming substrate-catalyst complexes. In addition, non-bonding interactions can be ancillary to a covalent bond and serve to fix the conformation of a reactive species. Exemplifying such strategies, the use of isothioureas in catalysis was initially reported by Birman and Okamoto, ${ }^{[6]}$ and has since been exploited

[a] Dr C. M. Young, Mr C. McLaughlin, Mr A. M. Woods, Dr A. de la Houpliere, Dr A. B. Frost, Prof. T. K Smith, Prof. A. M. Z. Slawin, Prof. A. D. Smith*

EaStCHEM School of Chemistry, University of St Andrews, North Haugh, St Andrews KY16 9ST (UK). E-mail: ads10@st-andrews.ac.uk

[b] Mr A. Elmi, Dr D. J. Pascoe, Prof. S. L. Cockroft* EaStCHEM School of Chemistry, University of Edinburgh, Joseph Black Building, David Brewster Road, Edinburgh EH9 3FJ (UK). E-mail: scott.cockroft@ed.ac.uk

[c] Ms R. K. Morris, Prof. P. H. Willoughby*

Chemistry Department, Ripon College, 300 W. Seward St. Ripon, WI 54971 (USA).

E-mail: willoughbyp@ripon.edu

[d] Dr K. B. Ling

Syngenta, Jealott's Hill International Research Centre, Bracknell, Berkshire RG42 6EY (UK).

Supporting information for this article is given via a link at the end of the document. by ourselves and others in a variety of enantioselective transformations. ${ }^{[7]}$ In their most common reactions, isothioureas are initially acylated to give $\mathrm{N}$-acyl isothiouronium intermediates that dictate the stereoselectivity in subsequent bond-forming events (Figure 1A). The nature of the acylating agent and reaction conditions provide general access to three distinct reactive species, namely acyl and $\alpha, \beta$-unsaturated acyl isothiouronium, and $\mathrm{C}(1)$-isothiouronium enolate intermediates (Figure $1 \mathrm{~A}){ }^{[7]} \mathrm{A}$ common structural feature of these activated intermediates is a $1,5-0 \cdot \cdots$ S contact that is proposed to fix the geometry of the acylated catalyst, increasing the electrophilicity of the carbonyl due to the interaction with a formally Lewis acidic sulfur atom, as well as providing facial discrimination in subsequent reaction processes. Indeed, preliminary crystallographic studies revealed the interatomic $\mathrm{O}-\mathrm{S}$ distance to be significantly shorter than the sum of the component van der Waals radii, while computational analyses have suggested that a syn-periplanar $1,5-\mathrm{O} \cdots \mathrm{S}$ relationship is energetically favored. ${ }^{[8]}$

The invoked $1,5-\mathrm{O} \cdot \cdots$ S contact can be broadly categorized as a chalcogen bond. ${ }^{[9]}$ Chalcogen bonds are secondary interactions specifically involving group 16 elements $(\mathrm{O}, \mathrm{S}, \mathrm{Se}$, etc. $),{ }^{[10]}$ and accordingly share several characteristics with

A: Established isothiourea reactivity

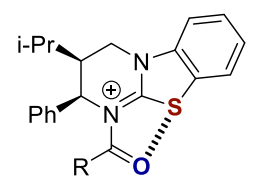
acyl ammonium
$\cdot$ acyl transfer
- kinetic resolution

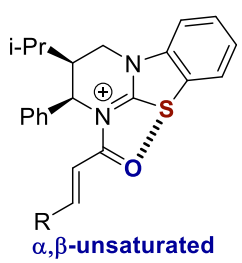

$\alpha, \beta$-unsaturated ammonium enolate acyl ammonium $\quad$ formal cycloadditions

- $\mathrm{C}-3$ electrophile

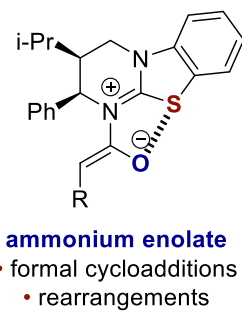

B: Chalcogen bonding catalysis: state of the art
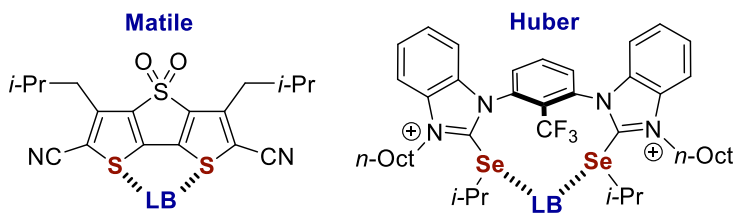

LB = Lewis base

C: This work: the role of chalcogens in isochalcogenourea catalysis
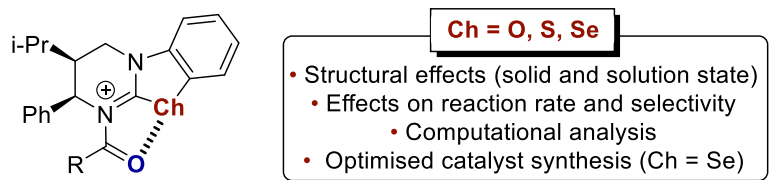

Figure 1. State-of-the-art in chalcogen bonding catalysis and application to isochalcogenoureas. 
their halogen (group 17) and pnictogen (group 15) bonding cousins. ${ }^{[11]}$ Chalcogen bonds have been observed in X-ray crystallographic analyses in a range of contexts ${ }^{[12]}$ and are proposed to be significant in diastereoselective reactions of chiral organoselenium compounds, as exemplified in pioneering work by Tomoda and Wirth among others. ${ }^{[13]}$ In a landmark publication, Matile reported the exploitation of chalcogen bonds in catalysis, using bis-thiophene derivatives for the reduction of quinolines and imines (Figure 1B, left). ${ }^{[14]}$ Similarly, Huber has demonstrated chalcogen bond donors as both stoichiometric promoters and organocatalysts (Figure 1B, right). ${ }^{[15]}$

The nature of $1,5-\mathrm{Ch} \cdot \cdots \mathrm{Ch}$ interactions was recently investigated by the Cockroft group using a model system bearing a close structural similarity to the $\mathrm{N}$-acylated isothiourea catalysts utilized within the Smith group and others. ${ }^{[16]}$ The combined experimental and theoretical investigation suggested that such intramolecular chalcogen bonds were dominated by orbital delocalization between a lone-pair donor and an antibonding acceptor orbital (e.g. $\left.n_{\mathrm{O}} \rightarrow \sigma_{\mathrm{S}-\mathrm{C})}\right)^{[17]}$ Building on this work, and by analogy to pnictogen and halogen bonding interactions, which increase in strength with increasing atomic number, we postulated that a series of catalyst congeners 1 - $\mathrm{Ch}$ where $\mathrm{Ch}=$ $\mathrm{O}, \mathrm{S}$, and $\mathrm{Se}$ could be used to probe the importance of 1,5$\mathrm{O} \cdot \cdots \mathrm{Ch}$ interactions in isochalcogenourea catalysis, with the heavier chalcogens expected to engage more strongly in chalcogen bonding (Figure 2A). In this manuscript we report experimental and computational analyses of isochalcogenoureacatalyzed reactions and demonstrate that intramolecular chalcogen bonds impart control over the conformation and stabilization of $\mathrm{N}$-acylated reaction intermediates (Figures 3 and 4). Accordingly, 1-Se demonstrates optimal rate and selectivity profiles across a range of reactions (Figures 5 and 6), consistent with the crucial importance of the $1,5-0 \cdots \cdot C h$ interaction.

Isothiourea $1-S$ is commercially available and readily prepared, ${ }^{[18]}$ and isourea 1-O was synthesized by an analogous route (Figure 2A). ${ }^{[18,19]}$ However, the corresponding route to the isoselenourea 1-Se gave low yields, ${ }^{[19]}$ necessitating the development of a new route to $1-\mathrm{Se}$. In a one-pot protocol, $\mathbf{2}^{[18 \mathrm{a}]}$ was added to phenyl isoselenocyanate $\mathbf{3}$ to generate selenourea 4, which was then cyclized to give $\mathbf{5}$ in what is the first reported seleno-Hugerschoff reaction (Figure 2B). ${ }^{[20,21]}$ Adapting the previously reported approach, in situ addition of $\mathrm{Et}_{3} \mathrm{~N}$ and $\mathrm{MsCl}$ followed by gentle heating affected cyclization to give isoselenourea $1-\mathrm{Se}$ in good yield. The reaction could be performed on a gram scale giving $1.1 \mathrm{~g}(3.1 \mathrm{mmol}) 1-\mathrm{Se}$ in $64 \%$ yield from 2 and 3. ${ }^{[22]} 1-O$ 1-S and 1-Se could all be stored for several months on the bench-top and pleasingly, all showed no toxicity against $\mathrm{HeLa}$ cells at concentrations $<1 \mathrm{~mm}$. ${ }^{[19]}$

With the 1-O, 1-S and 1-Se analogues in hand, the nature of the $1,5-\mathrm{O} \cdot \cdots \mathrm{Ch}$ interactions occurring within $\mathrm{N}$-acylated catalysts, was investigated. Crystalline $N$-naphthylacetyl isochalcogenouronium hexafluorophosphate salts $6-\mathrm{O}, 6-\mathrm{S}$ and 6-Se were prepared and subjected to X-ray structural analysis (Figure 3). Compound 6-O did not form an intramolecular 1,5$0 \cdot \cdots O$ chalcogen bond in the solid state, and instead exhibited an anti-coplanar conformation (Figure 3A). In contrast, 6-S and 6-Se possessed coplanar syn-conformations with $1,5-0 \cdot \cdots \mathrm{S} / \mathrm{Se}$
A: Isochalcogenourea catalysts

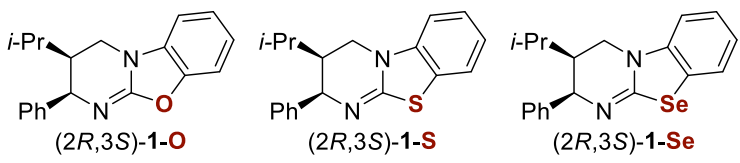

B: Synthesis of isoselenourea 1-Se
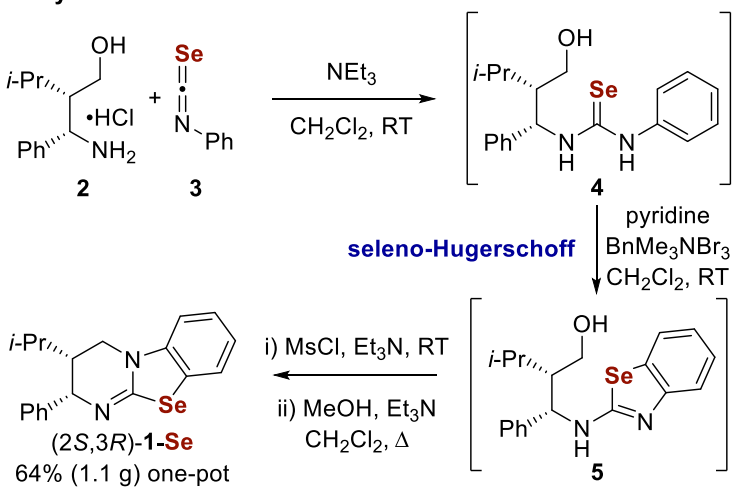

Figure 2. Optimized synthesis of 1-Se via seleno-Hugerschoff reaction.

interatomic distances shorter than the sum of their respective van der Waals radii. Consistent with a weakening of the carbonyl bond arising from $n_{O} \rightarrow \sigma^{*}$ S/Se-C delocalization, the IR stretching frequencies of the $\mathrm{C}=\mathrm{O}$ in $\mathbf{6 - S}$ and $6-\mathrm{Se}\left(1709 \mathrm{~cm}^{-1}\right.$ and 1713 $\left.\mathrm{cm}^{-1}\right)$ was significantly shifted compared to $6-\mathrm{O}\left(1748 \mathrm{~cm}^{-1}\right)$, and the ${ }^{13} \mathrm{C}$ NMR carbonyl chemical shifts in compounds 6-S and 6Se $\left(\delta_{\mathrm{C}} 174.5 \mathrm{ppm}\right.$ and $\left.174.0 \mathrm{ppm}\right)$ were deshielded compared to 6-O ( $\left.\delta_{\mathrm{c}} 169.7 \mathrm{ppm}\right)$ in $\mathrm{CDCl}_{3}$, consistent with the respective presence and absence of intramolecular chalcogen bonds (Figure 3). ${ }^{[23]}$ Density functional theory (DFT) calculations were then used to examine the physicochemical nature of the $1,5-0 \cdot \cdots \mathrm{Ch}$ interactions (Figure 3).

Dispersion-corrected ((wB97X-D/6-311G*) energy minimization calculations $\left(\Delta E_{\text {anti } \rightarrow \text { syn }}\right)$ reproduced the solid-state preference of 6-O for the anti-conformer $\left(\Delta E_{\text {anti } \rightarrow \text { syn }}=+20 \mathrm{~kJ} \mathrm{~mol}^{-1}\right)$, and 6-S and 6-Se for the syn-conformer $\left(E_{\text {anti } \rightarrow \text { syn }}=-17 \mathrm{~kJ} \mathrm{~mol}^{-1}\right.$ and $-28 \mathrm{~kJ} \mathrm{~mol}^{-1}$, respectively). Moreover, calculated Molecular Orbitals, Natural Bond Orbitals (NBO) and corresponding $2^{\text {nd }}$ order perturbation energies $\left(E^{(2)}\right)$ all supported the occurrence of stabilizing interactions arising from the delocalization of an acyl lone pair $(n)$ into an adjacent chalcogen-carbon $\sigma^{*}$ orbital in the sulfur and selenium derivatives $\left(E^{(2)}=20 \mathrm{~kJ} \mathrm{~mol}^{-1}\right.$ and $38 \mathrm{~kJ} \mathrm{~mol}^{-1}$, respectively) (Figure $3 \mathrm{~B}, \mathrm{C}$ ) with the $1,5-\mathrm{O} \cdot \cdots$ Se interactions consistently predicted to be stronger than $1,5-0 \cdots \mathrm{S}$ interactions. ${ }^{[19]}$ The delocalized orbitals are strikingly similar to those observed in molecular balances previously employed by the Cockroft group for measuring $1,5-\mathrm{O} \cdot \cdots \mathrm{Ch}$ chalcogen bonds (Table S9). ${ }^{[19]}$ Notably, both the calculated conformational energy differences $\left(\Delta E_{\text {anti } \rightarrow \text { syn }}\right)$ and NBO $2^{\text {nd }}$ order perturbation energies $\left(E^{(2)}\right)$ were up to five times more stabilizing in the cationic $N$ acylated catalysts 6-S and 6-Se compared to the neutral molecular balances utilized in our previous study (Figure S15). ${ }^{[17,19]}$ The similarity of these findings suggest that these intramolecular chalcogen bonds have important orbital 

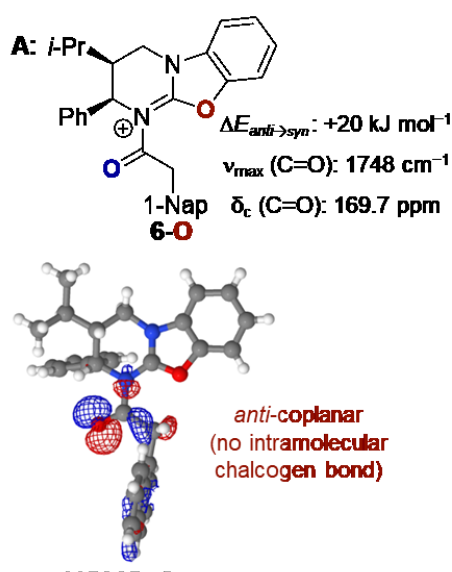

HOMO-9

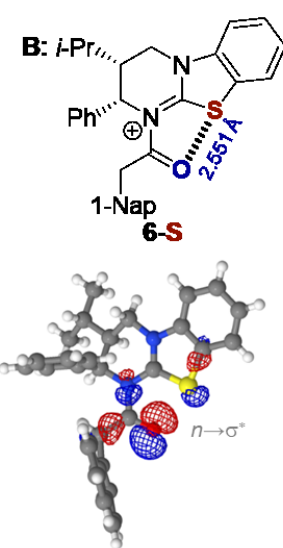

HOMO-8

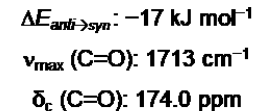

$\delta_{c}(C=O)=174.0 \mathrm{ppm}$

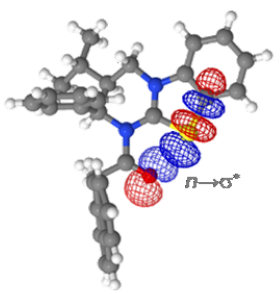

NBO $E_{n \rightarrow 0^{*}}^{(2)}: 20 \mathrm{~kJ} \mathrm{~mol}^{-1}$

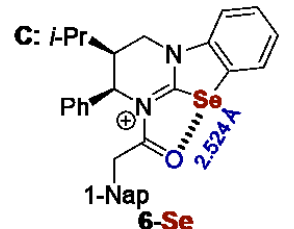

$\Delta E_{\text {anti } \rightarrow \text { syn }}:-28 \mathrm{~kJ} \mathrm{~mol}^{-1}$

$v_{\max }(\mathrm{C}=\mathrm{O}): 1709 \mathrm{~cm}^{-1}$

$\delta_{\mathrm{c}}(\mathrm{C}=\mathrm{O}): \mathbf{1 7 4 . 5} \mathrm{ppm}$

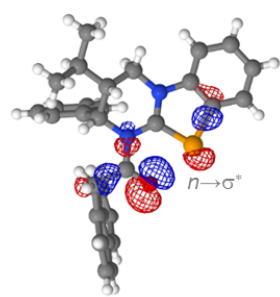

HOMO-7

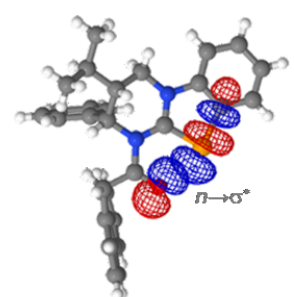

NBO $E_{n \rightarrow 0^{*}}^{(2)}: 38 \mathrm{~kJ} \mathrm{~mol}^{-1}$

Figure 3. X-ray crystallographic geometries of isochalcogenourea catalysts and corresponding experimental IR and ${ }^{13} \mathrm{C} N M R$ spectral data (CDCl $3298 \mathrm{~K}$ ) for the

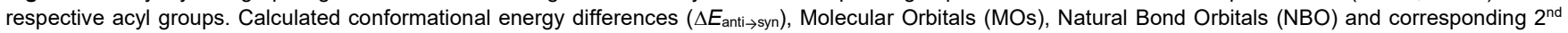
order perturbation energies $\left(E^{(2)}\right)$ all support the occurrence of stabilizing interactions arising from the delocalization of an acyl oxygen lone pair $(n)$ into an adjacent chalcogen-carbon $\sigma^{*}$ orbital in the sulfur and selenium derivatives (B and $\left.\mathbf{C}\right)$. No such stabilizing orbital interactions are present in the isourea derivative (A), which crystallizes as the anti-coplanar conformer. Crystallographic and computational details are provided in the SI. ${ }^{[19]}$ Calculations were performed using wB97X-D/6$311 \mathrm{G}^{*}$. Calculations performed using both wB97X-D or B3LYP on minimized and crystallographic structures gave the same energetic trends (Table S10)

contributions, which has previously been associated with decreased solvent competition. ${ }^{[24]}$ Thus, we next set out to confirm whether the identified chalcogen bonds were retained in $\mathrm{N}$-acylated intermediates in solution. Acetyl salts of 1-O, 1-S and 1-Se were prepared (Figure 4A). Reciprocal NOE enhancement was observed on irradiation of either proton environment highlighted in Figure $4 \mathrm{~A}$ when $\mathrm{Ch}=\mathrm{S}$ or Se, indicating spatial proximity of these protons and being consistent with the 1,5$\mathrm{O} \cdot \cdots \mathrm{Ch}$ interaction being maintained in solution. However, no NOE enhancement of these protons was observed when $\mathrm{Ch}=$ O. ${ }^{[25]}$ These observations are consistent with the conformational preferences of $\mathrm{N}$-acyl derivatives being the same in solution and the solid state (Figures 3 and $4 \mathrm{~A}$ ). Further studies in solution measured the equilibrium constants for the formation of $\mathrm{N}$ acylated species 9-Ch upon mixing each of the isochalcogenureas 1-O, 1-S, and 1-Se with isobutyric anhydride 8 in $\mathrm{CDCl}_{3}$ at $298 \mathrm{~K}$ (Figure 4B). ${ }^{[26]}$ An increase in the equilibrium constants with increasing atomic mass of the chalcogen acceptor was observed, consistent with the increasing stability of the acyl isochalcogenouronium species (and in accord with the analysis associated with Figure 3). Having characterized the nature of the

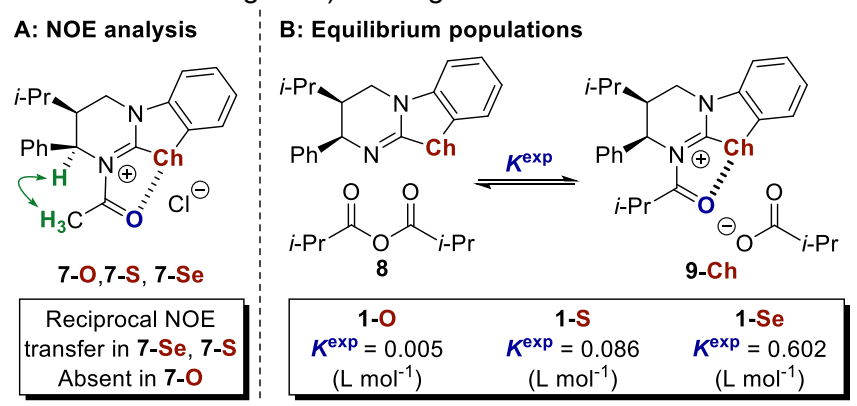

Figure 4. Solution-phase ${ }^{1} \mathrm{H}$ NMR experiments performed in $\mathrm{CDCl}_{3}$ at $298 \mathrm{~K}$, $500 \mathrm{MHz}$.
$1,5-0 \cdot \cdots$ Ch interactions (Figure 3 ) and their influence on the conformation and equilibrium populations of $\mathrm{N}$-acyl intermediates (Figures 3 and 4), we set out to quantify how varying the chalcogen atom in isochalogenourea catalysts influences catalytic activity (Figure 5). Pleasingly, both 1-S and 1-Se proved to be competent catalysts for the kinetic resolution of secondary alcohol 10 giving similar conversion ( $c=47 \%$ for both) and selectivity ( $s>200$ with both $1-S$ and 1-Se) (Figure 5A). ${ }^{[27,28]}$ In contrast, isourea 1-O, which lacks the ability to stabilize the $N$ acyl intermediate via chalcogen bonding, gave no observable acylation of the starting material (Figure 5A). Next, the challenging kinetic resolution of tertiary heterocyclic alcohol 12 was performed (Figure 5B). ${ }^{[15 f]}$ While isourea 1-O gave no conversion to ester $\mathbf{1 3}$, isoselenourea 1-Se gave good conversion (c $=45 \%$ ) and selectivity $(s=60)$ comparable to the isothiourea $1-S(c=54 \%, s$ $=60$ ). Moreover, the rate of acylation of enantiopure alcohol $(R)$ 12 was significantly increased in the presence of $1 \mathrm{~mol} \%$ of the isoselenourea catalyst 1-Se relative to isothiourea 1-S (Figure 5B, $\mathrm{t}_{1 / 2}=8$ mins vs. $\mathrm{t}_{1 / 2}=35$ mins). The experimentally observed catalytic activities presented in Figure 5 presumably reflect: i) the conformational preferences determined by the $1,5-\mathrm{O} \cdots \cdot \mathrm{Ch}$ interactions occurring in the $\mathrm{N}$-acylated intermediates (Figures 3 and 4) and ii) the concentration of the key acyl isochalcogenouronium intermediates as approximated by $K^{\exp }$ in Figure 4B. The observed rate enhancement using 1-Se presumably reflects kinetic acceleration of the elementary catalytic steps as well as thermodynamic stabilization of intermediates through exploiting these $1,5-\mathrm{O} \cdots \bullet \mathrm{Ch}$ interactions.

To further examine the catalytic ability of the 1-Se catalyst, kinetic resolutions of several tertiary alcohols were performed using a catalyst loading of only $500 \mathrm{ppm}$. For alcohol 12 conversion of $39 \%$ was obtained with $s=70$. This compared with $c=9 \%, s=70$ for the kinetic resolution of 12 catalyzed by 1-s (500 ppm). ${ }^{[18]}$ The reaction was general for a number of substrates varying both the $N$-substituent (14) and $R^{1}$ (15 and 16) 
to give $c=31-50 \%$ and $s=70-120$. Even particularly sterically congested alcohol 17 could be resolved $(c=28 \%, s=38)$ albeit

\begin{tabular}{|c|c|c|}
\hline \multicolumn{3}{|c|}{$\begin{array}{l}\text { A: Kinetic resolution of a } 2^{\circ} \text { alcohol } \\
\qquad \begin{array}{c}\mathrm{OH} \quad \begin{array}{c}(2 R, 3 S)-1-\mathrm{Ch}(1 \mathrm{~mol} \%) \\
i-\mathrm{Pr}_{2} \mathrm{NEt}(0.5 \mathrm{eq})\end{array}\end{array}\end{array}$} \\
\hline $\begin{array}{c}( \pm)-10 \\
\operatorname{Ar}=2-N a p\end{array}$ & PhMe, $-78{ }^{\circ} \mathrm{C}$ & $R)-10$ \\
\hline $\begin{array}{c}1-0 \\
c=<5 \%\end{array}$ & $\begin{array}{c}1-\mathrm{S} \\
\mathrm{c}=47 \%, s>200 \\
\mathrm{er}_{\text {ester }}=99: 1 \\
\mathrm{er}_{\text {alc. }}=94: 6\end{array}$ & $\begin{array}{c}1-\mathrm{Se} \\
\mathrm{c}=47 \%, s>200 \\
\mathrm{er}_{\mathrm{ester}}=>99: 1 \\
\mathrm{er}_{\mathrm{alc}}=94: 6\end{array}$ \\
\hline
\end{tabular}

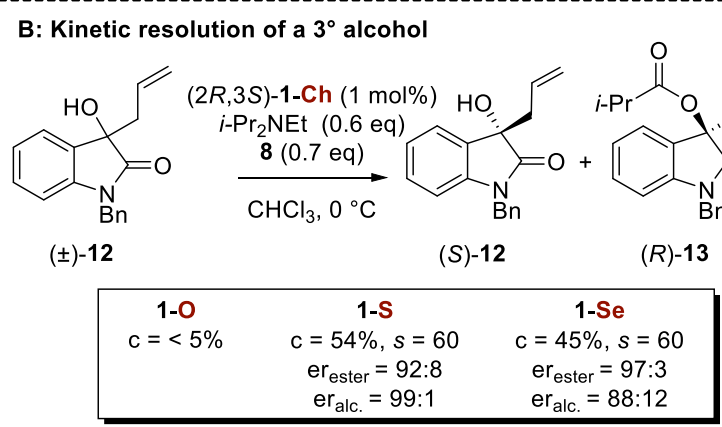

Acylation of $(R)-12(99: 1 \mathrm{er})$ using 1-S or 1-Se

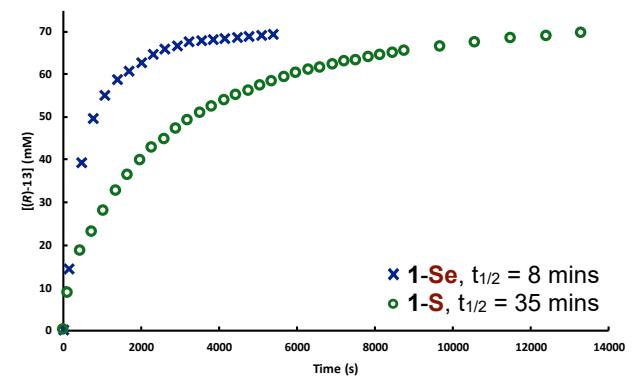

C: Kinetic resolution of $3^{\circ}$ alcohols at $500 \mathrm{ppm}$ catalyst loading<smiles>[R]N1C(=O)C([R])(O)c2ccccc21</smiles>

$( \pm)-12,14-17$
$(2 R, 3 S)-1-S e(500 \mathrm{ppm})$

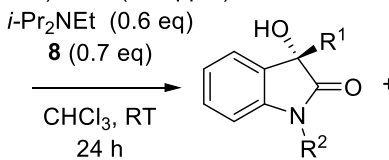

(S)-12,14-17

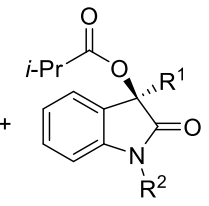

(R)-13,18-21

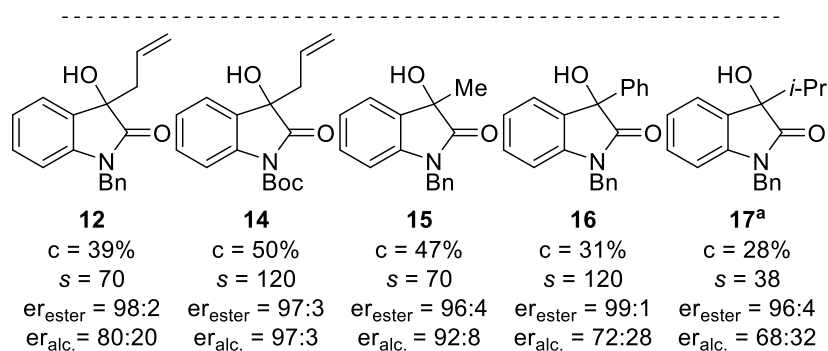

Figure 5. A and B. Comparison of isoselenourea catalyst activity in kinetic resolutions of secondary $(10)$ and tertiary $(12)$ alcohols. Starting concentrations for monitored reaction: $(R)-12$ (99:1 er; $80 \mathrm{~mm}), 1-\mathrm{Ch}(8 \mathrm{~mm}), i-\mathrm{Pr}_{2} \mathrm{NEt}(100 \mathrm{~mm})$. Reactions monitored in $\mathrm{CDCl}_{3}$ at $273 \mathrm{~K}$ using $500 \mathrm{MHz}{ }^{1} \mathrm{H}$ NMR spectroscopy.C
Kinetic resolution of tertiary alcohols at 500 ppm 1-Se. ${ }^{\left[{ }^{a}\right.}{ }_{i}-\mathrm{Pr}_{2} \mathrm{NEt}(0.8 \mathrm{eq}), 8$ (1.0 eq), reaction time: $73 \mathrm{~h}$.

with higher base and anhydride equivalencies (0.8 and 1.0 equivalents respectively) and with prolonged reaction time (3 days) (Figure 5C). ${ }^{[19]}$ The remarkable catalytic activity and selectivity of 1-Se counters the common perception that organocatalysis requires high catalyst loading. ${ }^{[29]}$

To determine whether intramolecular $1,5-\mathrm{O} \cdot \cdots \cdot \mathrm{Ch}$ interactions governed catalysis beyond acyl transfer processes, the activity of the 1-Ch series was examined in reactions proposed to proceed via $\alpha, \beta$-unsaturated acyl isothiouronium and $C(1)$-isothiouronium enolate intermediates (Figure $1 \mathrm{~A}$, centre and right). ${ }^{[30,18]}$ The isochalcogenourea-catalyzed Michael addition of nitromethane to ester 23 gave the amide product in less than 5\% yield and 45:55 er when 1-O was used (Figure 6A). In contrast, both the 1-S and 1-Se catalysts gave $\mathbf{2 4}$ in 55\% yield and $\sim 95: 5$ er. Monitoring the rate of formation of $\mathbf{2 4}$ by ${ }^{19} \mathrm{~F}\left\{{ }^{1} \mathrm{H}\right\}$ NMR spectroscopy showed a significant increase in rate with 1-Se $\left(\mathrm{t}_{1 / 2}=8 \mathrm{mins}\right)$ compared with 1-S $\left(t_{1 / 2}=145\right.$ mins) (Figure $\left.6 \mathrm{~A}\right)$. Using a similar approach, the relative rates of isochalcogenourea-catalyzed Michael additionlactonization reactions, proposed to proceed via a $\mathrm{C}(1)$ isochalcogenouronium enolate intermediate (Figure 1B, right) were next examined (Figure 6B). ${ }^{[18 a]}$ Isourea 1-O gave the desired lactone 29 in a moderate $46 \%$ yield and $87: 13 \mathrm{dr}$, but with negligible enantiocontrol (53:47 er). Catalysis using either 1-S or 1-Se was again effective, yielding 29 in $80 \%$ yield, $84: 16 \mathrm{dr}$ and 95:5 er when using 1-S, and 95\% yield, $84: 16 \mathrm{dr}$ and 98:2 er when using 1-Se. Again, a significant increase in the rate of product formation (30) was observed using 1-Se ( $t_{1 / 2}=11$ mins) compared to $1-\mathrm{S}\left(\mathrm{t}_{1 / 2}=122 \mathrm{mins}\right)$ when the reaction was monitored by ${ }^{19} \mathrm{~F}\left\{{ }^{1} \mathrm{H}\right\}$ NMR spectroscopy (Figure 6B).

In conclusion, the importance of $1,5-\mathrm{O} \cdots \mathrm{Ch}$ interactions in isochalcogenourea catalysis was confirmed through theoretical and experimental studies. Computations, X-ray crystallography, and NMR spectroscopic analysis of $\mathrm{N}$-acylated catalysts all indicated the importance of $1,5-0 \cdot \cdots \mathrm{Ch}$ interactions in governing the conformation and stability of these key reactive intermediates. DFT, molecular orbital, and NBO calculations suggest that the nature of the $1,5-\mathrm{O} \cdots \cdot \bullet \mathrm{Ch}$ interaction is consistent with $n_{\mathrm{O}} \rightarrow \sigma^{*} \mathrm{Ch-C}$ electron delocalisation. Experiments in solution are consistent with the stabilizing intramolecular chalcogen bond being maintained for 1-S and 1-Se, leading to greatly enhanced catalytic activity compared to the largely inactive 1-O congener. The consistent enantioselectivity observed in reactions catalyzed by 1-S and 1-Se indicates a consistent energy difference between the diastereomeric transition states in the assumed enantiodetermining step. However, the enhanced catalytic activity of 1Se compared to $1-\mathrm{S}$ is consistent with most favorable $\mathrm{O} \cdots \mathrm{Ch}$ interactions providing enhanced stabilization of acylated catalytic intermediates and interposed transition states. We establish 1-Se as an efficient and highly selective organocatalyst, applicable at ppm levels, in the challenging kinetic resolution of heterocyclic tertiary alcohols. The first reported seleno-Hugerschoff reaction was utilized to synthesize 1-Se reliably and on a gram-scale, enhancing the potential application of this promising Lewis-base catalyst. 
A: $\alpha, \beta$-Unsaturated acyl-isochalcogenouronium catalysis ${ }^{a}$

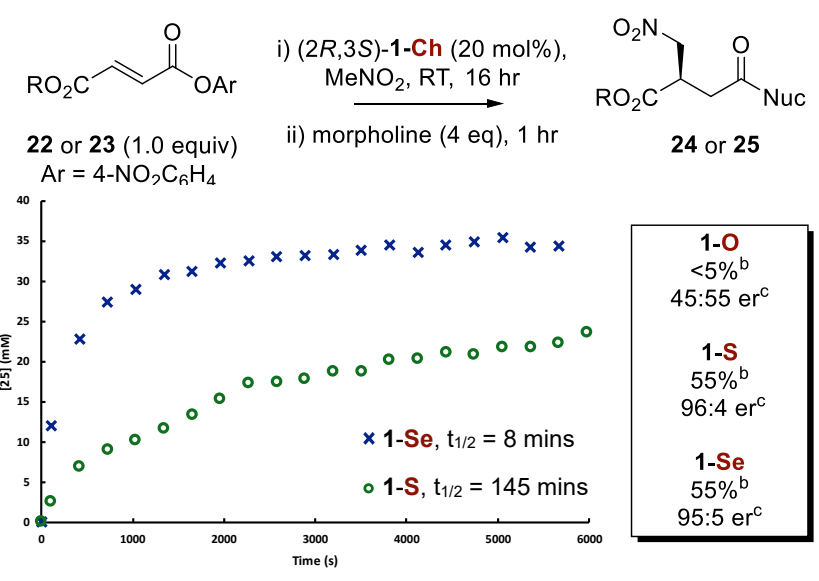

B: Isochalcogenouronium enolate catalysis ${ }^{d}$

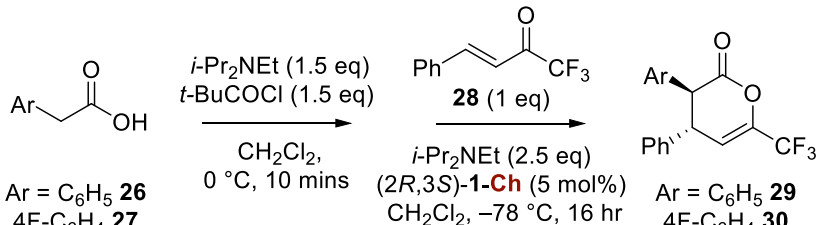
$4 \mathrm{~F}-\mathrm{C}_{6} \mathrm{H}_{4} 27$

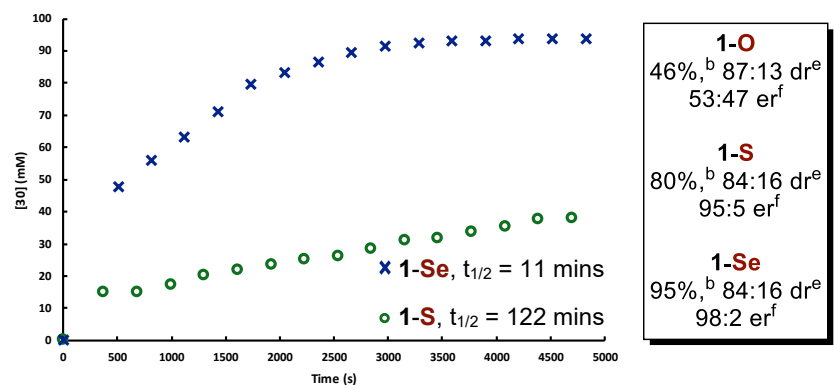

Figure 6. Isochalcogenoureas in catalysis. A. $\alpha, \beta$-Unsaturated acyl isochalcogenouronium catalysis. ${ }^{a}$ For yield determination, 22 to $24 \mathrm{R}=\mathrm{Et}, 1.0$ equiv, Nuc = morpholine; For kinetics, starting concentrations: 23 to $25(R=4$ $\left.\mathrm{FC}_{6} \mathrm{H}_{4} \mathrm{CH}_{2}\right)(100 \mathrm{~mm}), 1-\mathrm{Ch}(12 \mathrm{~mm}), \mathrm{MeNO}_{2}: \mathrm{CHCl}_{3}$ 9:1, $\mathrm{C}_{6} \mathrm{D}_{6}$ capillary, , ${ }^{19} \mathrm{~F}\left\{{ }^{1} \mathrm{H}\right\}$, $476 \mathrm{MHz}, \mathrm{Nuc}=4-\mathrm{NO}_{2} \mathrm{C}_{6} \mathrm{H}_{4} \mathrm{O} ;{ }^{b}$ Isolated yield; ${ }^{\mathrm{c}}(R):(S)$ as determined by chiral HPLC analysis. B. Isochalcogenouronium enolate catalysis. $d$ For yield determination, $\mathrm{Ar}=\mathrm{C}_{6} \mathrm{H}_{5}$; For kinetics, starting concentrations: $27\left(\mathrm{Ar}=4-\mathrm{FC}_{6} \mathrm{H}_{4}\right.$, $100 \mathrm{~mm})$, catalyst $(0.25 \mathrm{~mm})$, enone $28(100 \mathrm{~mm}), i-\mathrm{Pr}_{2} \mathrm{NEt}(250 \mathrm{~mm}), \mathrm{CD}_{2} \mathrm{Cl}_{2},-$ $70{ }^{\circ} \mathrm{C},{ }^{19} \mathrm{~F}\left\{{ }^{1} \mathrm{H}\right\}, 476 \mathrm{MHz}$. ${ }^{\mathrm{b}}$ Isolated yield. ${ }^{\mathrm{e}}$ Determined by ${ }^{1} \mathrm{H}$ NMR spectroscopic analysis of the crude reaction mixture. ${ }^{f}(3 S, 4 S):(3 R, 4 R)$ as determined by chiral HPLC analysis.

\section{Acknowledgements}

We thank Liam McGeachie for insightful discussions and Siobhan Smith for her help with NMR experiments. Syngenta (Case Award to DJP) and a Philip Leverhulme Prize for funding (SLC, AE). RKM and PHW are grateful to the American Chemical Society Petroleum Research Fund and National Science Foundation (NSF-MRI: CHE-1429616).

Keywords: Organocatalysis $\cdot$ Chalcogen bonding $\bullet$ isothiourea - isoselenourea $\bullet 1,5-\mathrm{O} \cdot \bullet \cdot \mathrm{Ch}$

\section{References}

[1] a) J. -M. Lehn, Science 2002, 295, 2400-2403; b) J. Černý, P. Hobza Phys. Chem. Chem. Phys. 2007, 9, 5291-5303; c) I. K. Mati, S. L. Cockroft, Chem. Soc. Rev. 2010, 39, 4195-4205 d) M. M. MonteroCampillo, O. Brea, O. Mó, I. Alkorta, J. Elguero, M. Yáñez, Phys. Chem. Chem. Phys. 2019, 21, 2222-2233.

[2] A.G. Doyle, E. N. Jacobsen, Chem. Rev., 2007, 107, 5713-5743.

[3] T. M. Beale, M. G. Chudzinski, M. G. Sarwar, M. S. Taylor, Chem. Soc. Rev. 2013, 42, 1667-1680.

[4] C. R. Kennedy, S. Lin, E. N. Jacobsen, Angew. Chem. Int. Ed. 2016 55 ,12596-12624; Angew. Chem. 2016, 128, 12784-12814.

[5] Y. Zhao, Y. Cotelle, N. Sakai, S. Matile, J. Am. Chem. Soc. 2016, 138, 4270-4277

[6] a) V. B. Birman, X. Li, Org. Lett. 2006, 8, 1351-1354; b) M. Kobayachi, S. Okamoto, Tetrahedron Lett. 2006, 47, 4347-4350.

[7] For an excellent review of the area, see: J. Merad, J. -M. Pons, O. Chuzel, C. Bressy, Eur. J. Org. Chem. 2016, 5589-5610.

[8] a) M. E. Abbasov, B. M. Hudson, D. J. Tantillo, D. Romo, J. Am. Chem Soc. 2014, 136, 4492; b) V. B. Birman, X. Li, Z. Han, Org. Lett. 2007, 9 37-40; c) E. R. T. Robinson, C. Fallan, C. Simal, A. M. Z. Slawin, A. D. Smith, Chem. Sci. 2013, 4, 2193-2200; d) E. R. T. Robinson, D. M Walden, C. Fallan, M. D. Greenhalgh, P. H. -Y. Cheong, A. D. Smith, Chem. Sci. 2016, 7, 6919-6927; e) T. H. West, D. M. Walden, J. E. Taylor, A. C. Brueckner, R. C. Johnson, P. H.-Y. Cheong, G. C. Lloyd-Jones, A. D. Smith, J. Am. Chem. Soc. 2017, 139, 4366-4375; f) M. D. Greenhalgh, S. M. Smith, D. M. Walden, J. E. Taylor, Z. Brice, E. R. T. Robinson, C. Fallan, D. B. Cordes, A. M. Z. Slawin, H. C. Richardson, M. A. Grove, P H-Y. Cheong, A. D. Smith, Angew. Chem. Int. Ed. 2018, 57, 3200-3206; Angew. Chem. 2018, 130, 3254-3260.

[9] C. B. Aakeroy, D. L. Bryce, G. R. Desiraju, A. Frontera, A. C. Legon, F. Nicotra, K. Rissanen, S. Scheiner, G. Terraneo, P. Metrangolo, G. Resnati, Pure Appl. Chem. 2019, https://doi.org/10.1515/pac-2018-0713.

[10] L. Brammer, Faraday Discussions, 2017, 203, 485-507.

[11] For reviews see: a) K. T. Mahmudov, M. N. Kopylovich, M. F. C. G. da Silva, A. J. L. Pombeiro, Dalton Trans. 2017, 46, 10121-10138; b) S. Benz, A. I. Poblador-Bahamonde, N. Low-Ders, S. Matile, Angew. Chem Int. Ed., 2018, 57, 5408-5412; Angew. Chem. 2018, 130, 5506-5510; c) L. Vogel, P. Wonner, S. M. Huber, Angew. Chem. Int. Ed. 2019, 58, 1880-1891; Angew. Chem., 2019, 131, 1896-1907.

[12] a) R. E. Rosenfield Jr., R. Pathasarathy, J. D. Dunitz, J. Am. Chem. Soc 1977, 99, 4860-4862; b) R. Laitinen, R. Steudel, R. Weiss, J. Chem. Soc Dalton Trans., 1986, 1095-1100; c) F. T. Burling, B. M. Goldstein, J. Am Chem. Soc. 1992, 114, 2313-2320; d) B. R. Beno, K. -S. Yeung, M. D. Bartberger, L. D. Pennington, N. A. Meanwell, J. Med. Chem. 2015, 58, 4383-4438.

[13] For a review of 1,5-chalcogen bonding interactions in organoselenium chemistry, see: A. J. Mukherjee, S. S. Zade, H. B. Singh, R. B. Sunoj, Chem. Rev. 2010, 110, 4357-4416. For selected examples in catalysis see: a) S.-i Fukuzawa, K. Takahashi, H. Kato, H. Yamazaki, J. Org. Chem. 1997, 62, 7711-1716; b) T. Wirth, S. Haüptli, M. Leuenberger Tetrahedron: Asymmetry 1998, 9, 547-550; c) M. Tiecco, L. Testaferri, C. Santi, C. Tomassini, F. Marini, L. Bagnoli, A. Temperini, Tetrahedron Asymmetry 2000, 11, 4645-4650; d) M. Tiecco, L. Testaferri, C. Santi, C. Tomassini, F. Marini, L. Bagnoli, A. Temperini, Chem. - Eur. J. 2002 8, 1118-1124; r) D. M. Browne, O. Niyomura, T. Wirth, Org. Lett. 2007, 9, 3169-3171; f) Y. Kawamata, T. Hashimoto, K. Maruoka, J. Am. Chem. Soc. 2016, 138, 5206-5209; g) K. Fujita, M. Iwaoka, S. Tomoda, Chem Lett.1994, 23, 923-926; h) K. Fujita, K. Murata, M. Iwaoka, S. Tomoda, J. Chem. Soc., Chem. Commun. 1995, 1641-1642; i) K. Fujita, K. Murata, M. Iwaoka, S.Tomoda, Tetrahedron Lett. 1995, 36, 5219-5222; j) T. Wirth, Angew. Chem. 1995, 107, 1872-1873; Angew. Chem. Int. Ed. 1995, 34, 1726-1728.

[14] S. Benz, J. López-Andarias, J. Mareda, N. Sakai, S. Matile, Angew. Chem, Int. Ed. 2017, 56, 812-815; Angew. Chem. 2017, 129, 830-833 
[15] a) P. Wonner, L. Vogel, M. Düser, L. Gomes, F. Kneip, B. Mallick, D. B. Werz, S. M. Huber, Angew. Chem, Int. Ed. 2017, 56, 12009-12012; Angew. Chem. 2017, 129, 12172-12176; b) P. Wonner, L. Vogel, F. Kniep, S. M. Huber, Chem. Eur. J. 2017, 23, 16972-16975; c) P. Wonner, A. Dreger, E. Engelage, S. M. Huber, Angew. Chem. Int. Ed. 2019, 10.1002/anie.201910639, Angew. 2019, 10.1002/ange.201910639.

[16] D. J. Pascoe, K. B. Ling, S. L. Cockroft, J. Am. Chem. Soc. 2017, 139 , 15160-15167.

[17] G. R. Desiraju, P. S. Ho, L. Kloo, A. C. Legon, R. Marquardt, P. Metrangolo, P. Politzer, G. Resnati, K. Rissanen, Pure Appl. Chem. 2013, 85, 1711-1713.

[18] a) L. C. Morrill, J. Douglas, T. Lebl, A. M. Z. Slawin, D. J. Fox, A. D. Smith Chem. Sci. 2013, 4, 4146-4155. b) Commercially available from Apollo CAS: $1203507-02-1$.

[19] See electronic supporting information for details.

[20] H. Hugerschoff, Chem. Ber. 1901, 34, 3130-3135. (b) H. Hugerschoff, Chem. Ber. 1903, 36, 3121-3134

[21] A. D. Jordan, C. Luo, A. B. Reitz, J. Org. Chem. 2003, 68, 8693-8696.

[22] Both $(2 S, 3 R)$ and $(3 R, 2 S)$ enantiomers of 1 -Se were prepared in this study. The seleno-Hugerschoff development and gram scale synthesis were performed giving $(2 S, 3 R)-1-S e$. Further reactions and analysis were performed using $(2 R, 3 S)-1-S e .^{[18]}$

[23] The instability of acyl salts of 1-O to hydrolysis meant that comparative data in multiple solvents to confirm the weakening effect on the $\mathrm{C}=\mathrm{O}$ bond could not be reliably collected.

[24] a) D. H. R. Barton, M. B. Hall, Z. Lin, S. I. Parekh, J. Reibenspies, J. Am. Chem. Soc. 1993, 115, 5056-5059; b) M. Iwaoka, H Komatsu; T Katsuda; S Tomoda, J. Am. Chem. Soc. 2002, 124, 1902-1909; c) M Iwaoka, H. Komatsu, T. Katsuda, S. Tomoda, J. Am. Chem. Soc. 2004 126, 5309-5317; M. G. Sarwar, B. Dragisic, L. J. Salsberg, C. Gouliaras, M. S. Taylor, J. Am. Chem. Soc. 2010, 132, 1646-1653; e) C. C. Robertson, R. M. Perutz, L. Brammer, C. A. Hunter, Chem. Sci. 2014, 5 4179-4183.

[25] Connectivity between the acyl unit and the catalyst framework was confirmed by ${ }^{1} \mathrm{H},{ }^{13} \mathrm{C}-\mathrm{HMBC}$ experiments.

[26] Equilibrium constants were calculated using equation: $K^{\exp }=[9-\mathrm{Ch}] /[1$ Ch][8] (equation 1). This calculation assumes the ammonium salt is a tight ion pair defined by one concentration. It is, however, feasible that the equilibrium constant could be defined by the equation $K^{\exp }=[a c y l$ ammonium][isobutyrate]/[1-Ch][8] (equation 2) where the acyl ammonium and isobutyrate are considered separate species. Equilibrium constants calculated using equation 2 are given in the supporting information and demonstrate the same trend. ${ }^{[18]}$ Units have been retained for $K^{\exp }$ values as they are calculated using concentrations determined under non-reference state conditions rather than activities.

[27] S. F. Musolino, O. S. Ojo, N. J. Westwood, J. E. Taylor, A. D. Smith, Chem. Eur. J. 2016, 22, 18916-18922.

[28] a) Selectivity factor $(s)$ is defined is defined as the rate constant for the reaction of the fast-reacting enantiomer divided by the rate constant for the slow-reacting enantiomer and is calculated using equations defined by Kagan: H. B. Kagan, J.-C. Fiaud in Topics in Stereochemistry, Vol. 18 (Eds.: Ernest L. Eliel, Samuel H. Wilen), John-Wiley and Sons, New York, 1988, pp. 249-330; b) For a discussion on the use selectivity factor $(s)$ see: M. D. Greenhalgh, J. E. Taylor, A. D. Smith, Tetrahedron, 2018, 74, 5554-5560.

[29] a) For a review, see: F. Giacalone, M. Gruttadauria, P. Agrigento, R. Noto, Chem. Soc. Rev. 2012, 41, 2406-2447; b) For a recent example of low organocatalyst loading, see: H. Y. Ba, D. Höfler, P. S. J. Kaib, P. Kasaplar, C. Kanta De, A. Döhring, S. Lee, K. Kaupmees, I. Leito, B. List, Nat. Chem. 2018, 10, 888-894.

[30] A. Matviistsuk, M. D. Greenhalgh, D. -J. Barrios Antúnez, A. M. Z. Slawin, A. D. Smith, Angew. Chem. Int. Ed. 2017, 56, 12282-12287; Angew. Chem. 2017 129, 12450-12455.

[31] The research data underpinning this publication can be found at DOI: https://doi.org/10.17630/2a46952f-ed2c-4145-9dcd-ad1d2634e0a2 
Entry for the Table of Contents (Please choose one layout)

Layout 1:

\section{COMMUNICATION}

Conformational and computational analyses of $\mathrm{N}$ acyl isochalcogenouronium species and comparison with kinetic data demonstrate the significance of $1,5-0 \cdot \cdots \mathrm{Ch}$ interactions in enantioselective catalysis. The selenium analogue demonstrates enhanced rate and selectivity profiles across a range of reaction processes compared to its oxygen and sulfur
$\mathrm{Ch}=\mathrm{O}, \mathrm{S}, \mathrm{Se}$

Structural effects (solid and solution state) - Effects on reaction rate and selectivity - Computational analysis

- Optimised catalyst synthesis $(\mathrm{Ch}=\mathrm{Se})$
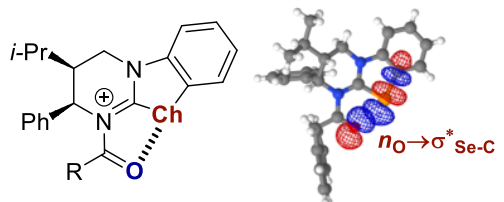

Claire M. Young, ${ }^{a}$ Alex Elmi, ${ }^{b}$ Dominic J

Pascoe, ${ }^{b}$ Rylie K. Morris, ${ }^{c}$ Calum McLaughlin, ${ }^{a}$ Andrew D. Woods, ${ }^{a}$ Aileen B. Frost, ${ }^{a}$ Alix de la Houpliere, ${ }^{a}$ Kenneth B. Ling, ${ }^{d}$ Terry K. Smith, ${ }^{a}$ Alexandra M. Z. Slawin, ${ }^{a}$ Patrick $H$. Willoughby, ${ }^{c *}$ Scott L. Cockroft ${ }^{b *}$ and Andrew D. Smith $^{\text {** }}$

Page No. - Page No.

The Importance of 1,5-Oxygen •••Chalcogen Interactions in Enantioselective Isochalcogenourea Catalysis

Layout 2:

\section{COMMUNICATION}

((Insert TOC Graphic here))
Author(s), Corresponding Author(s)*

Page No. - Page No.

Title

Text for Table of Contents

[a] Dr C. M. Young, Mr C. McLaughlin, Mr A. Woods, Dr A. de la Houpliere, Dr A. B. Frost, Prof. T. K Smith, Prof. A. M. Z. Slawin, Prof. A. D. Smith*

EaStCHEM School of Chemistry, University of St Andrews, North Haugh, St Andrews KY16 9ST (UK).

E-mail: ads10@st-andrews.ac.uk

[b] Dr D. J. Pascoe, Mr A. Elmi, Prof. S. L. Cockroft ${ }^{\star}$ EaStCHEM School of Chemistry, University of Edinburgh, Joseph Black Building, David Brewster Road, Edinburgh EH9 3FJ (UK). E-mail: scott.cockroft@ed.ac.uk

[c] Ms R. K. Morris, Prof. P. H. Willoughby*

Chemistry Department, Ripon College, 300 W. Seward St., Ripon, WI 54971 (USA)

E-mail: willoughbyp@ripon edu 